\title{
FOM -- An Online Reservation and Fiscal Management System for Shared Facilities
}

\author{
Shu-You Li and Vinayak P. Dravid*
}

Materials Science \& Engineering, Electron Probe Instrumentation Center, NUANCE User Facilities, Northwestern University, Evanston, IL 60208

Other than advanced functional instrumentation, a successful user facility also depends on two equally important factors: technical support and fiscal management. While technical support needs expertise and professionals, fiscal management often proves much more time consuming. Facility staff has to spend lot of their precious technical time on such mundane tasks as accepting new user applications, arranging training times, tracking instruments' usage, sending out billing invoices, etc. To make our lives easier and those of numerous facility colleagues around the world, we designed the Facility Online Manager (FOM).

FOM is an online (internet) accounting system for multi-user service facilities. Authorized users can reserve and access equipment online. The software's security controls enable facility managers to limit equipment usage to authorized groups and individuals. Security controls apply rules to restrict equipment usage in accordance with the user's level of training for the procedure and equipment in question. FOM supports automated billing, it maintains a real-time activity log, and provides numerous reports related to usage, billing and the like.

Figure 1 shows the principle of the security controls of FOM. The first gateway of FOM is the central server. The access to FOM central server is controlled by password database and (optional) IP range. The FOM central server communicates with local control PC via secured internet connections. When the local control PC receives ON/OFF signals from central server, it turns on/off the relay boxes corresponding to certain instruments.

All functions are available online. FOM supports multiple rates by which customers are charged (including training rates), and supports multiple user types that include repair personnel, outside trainees, etc. Depending upon an individual's skill level and the procedure and equipment he will apply and use, some users are permitted 24 hour access, while others are permitted usage only during an 8 hour period. Facility Online Manager provides a host of additional features that include information related to equipment and users, warnings prior to user expiration, tracking by user, the ability to charge for materials, links to online manuals, assistance request capability, activity reports for user groups, self service or service modes, quick view of status for all equipment, warning to users when equipment is down, reservation cancellation, warning when consumable stock is about to run out, etc. Figure 2 shows a screen shot of FOM while a user is requesting an "express login".

We also noticed some commercial online scheduling software and other home-made facility scheduling programs [1-3]. Their difference to FOM will be discussed in the presentation.

A demo of FOM is provided at the following link. http://www.nuance.northwestern.edu/fom (Click "Free Test of this Software."). 


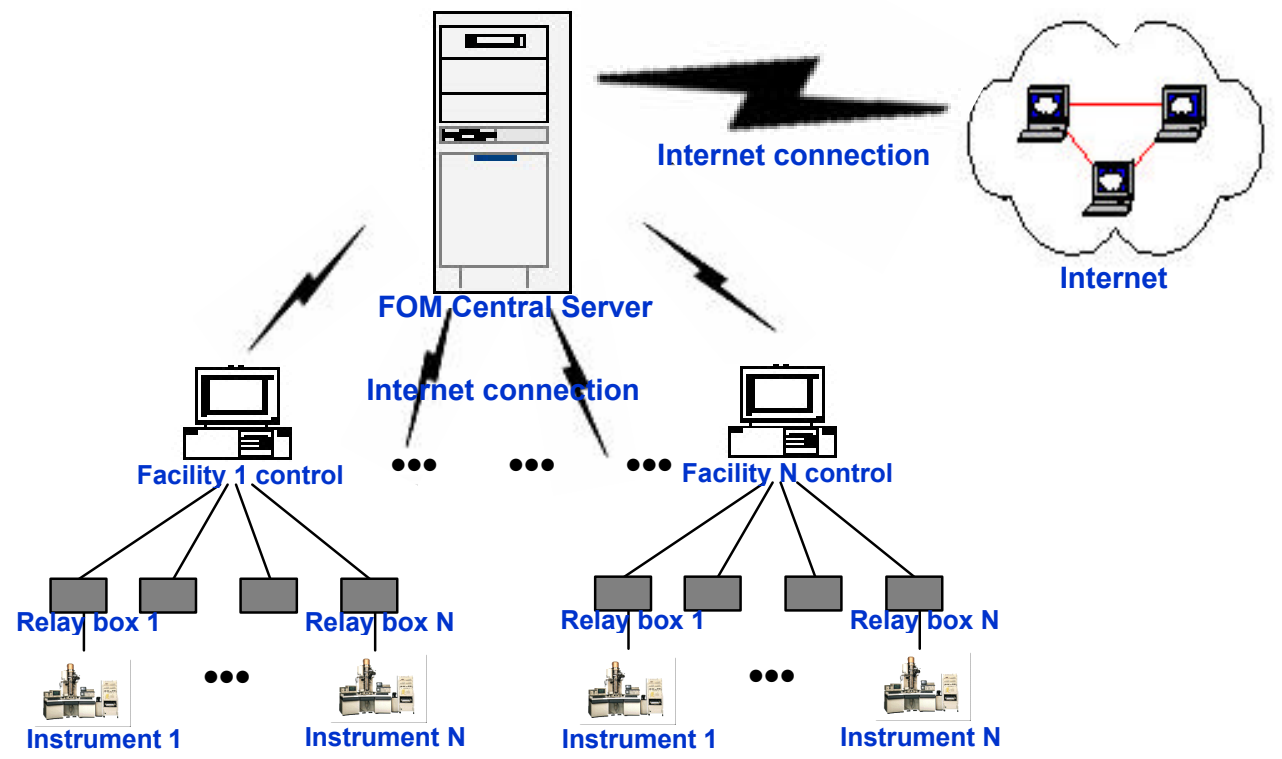

Figure 1. Schematic drawing of security controls of FOM.

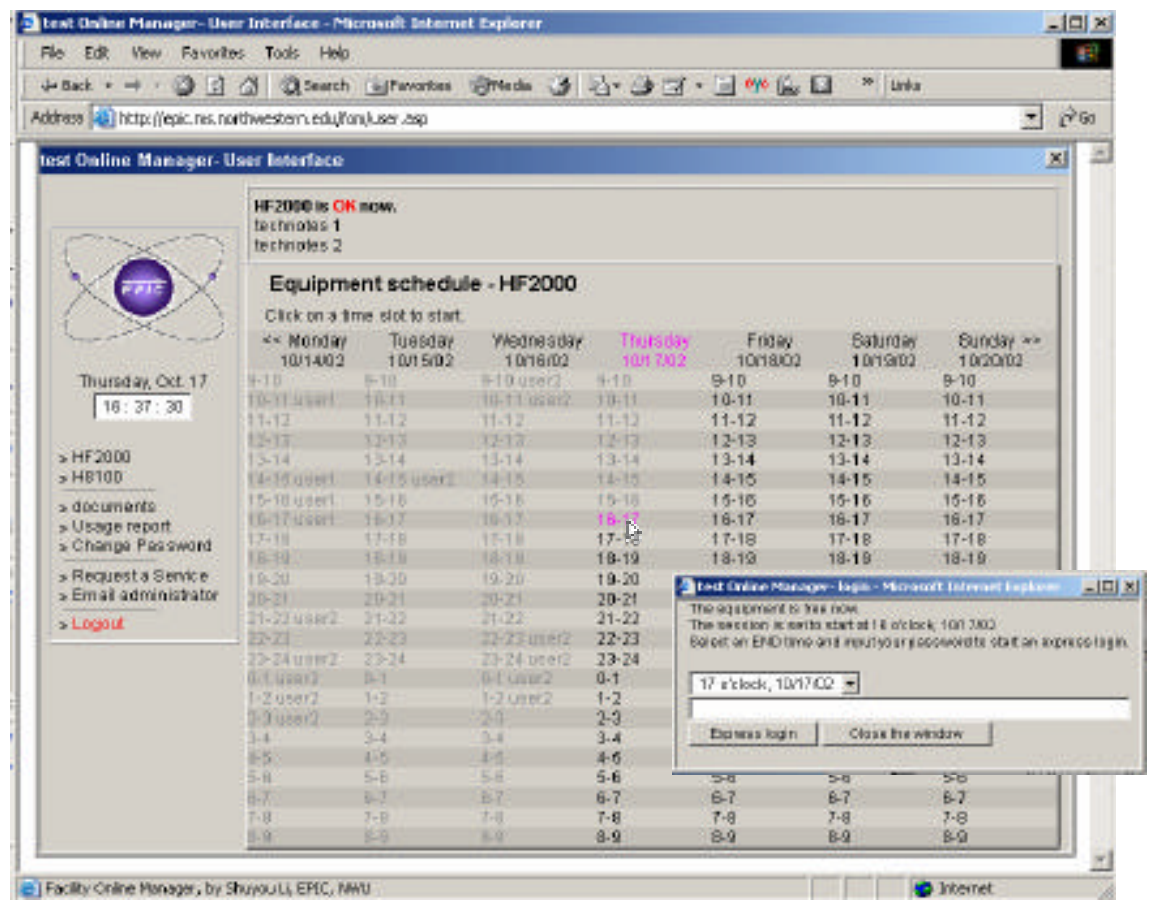

Figure 2. A screen shot of Facility Online Manager.

\section{References}

[1] http://www.biochem.northwestern.edu/Keck/Sign-up.html

[2] http://wilfred.berkeley.edu/ gordon/www-sched/

[3] http://www.brownbearsw.com/

*Corresponding author: Prof. Vinayak P. Dravid, Director, NUANCE User Facilities, 2220 Campus Drive, 1133 Cook Hall, Northwestern University, Evanston, IL 60208-3108, USA, Ph.: (847) 467-1363, Fax: (847) 467-6573, E-mail: v-dravid@northwestern.edu 